\title{
Temperature and velocity conditions of air flow in vertical channel of hinged ventilated facade of a multistory building.
}

\author{
Elena Statsenko ${ }^{2, *}$, Anastasia Ostrovaia ${ }^{2}$ and Andrey Pigurin ${ }^{1}$ \\ ${ }^{1}$ Moscow State University of Civil Engineering, Russia, 129337, Moscow, Yaroslavskoye shosse, 26 \\ ${ }^{2}$ Peter the Great St.Petersburg Polytechnic University, Polytechnicheskaya 29, 195251, St.Petersburg, \\ Russia
}

\begin{abstract}
This article considers the influence of the building's tallness and the presence of mounting grooved lines on the parameters of heat transfer in the gap of a hinged ventilated facade. A numerical description of the processes occurring in a heat-gravitational flow is given. The average velocity and temperature of the heat-gravitational flow of a structure with open and sealed rusts are determined with unchanged geometric parameters of the gap. The dependence of the parameters influencing the thermomechanical characteristics of the enclosing structure is derived depending on the internal parameters of the system. Physical modeling of real multistory structures is performed by projecting actual parameters onto a reduced laboratory model (scaling).
\end{abstract}

\section{Introduction}

High thermal properties are considered one of the main reasons for using hinged ventilated facades in modern high-rise construction. The principle of this system is that there are heatgravitational currents between thermal insulation and facing layer in the ventilated gap. They appear as a consequence of the action of the volume force caused by the difference in densities. There are three main types of air filtration in the designs of external fences: transverse, longitudinal and internal. All three types are possible in exterior walls with ventilated facades. The protection from air filtration is especially relevance in construction of high-rise buildings. Filtration for such buildings can wipe-out all the heat-protective characteristics of the exterior walls.

Ideally, the natural flow of air in the gap allows the wall to be permanently in a dry state, preventing the formation of condensation in the insulator layer. But the design features of each individual enclosing structure, including its technological grooved lines, affect the air velocity in the vertical channel, which also affects the temperature and humidity conditions of the enclosing structures. The article considers the effect of grooved lines and the tallness of a building on the velocity and temperature of air in a vertical ventilated gap.

\footnotetext{
* Corresponding author: staclena@mail.ru
} 


\section{Literature review}

At the present times hanging ventilated facades building is relevant to many Russian and foreign scientists. A major contribution to study of free-convective current in vertical ventilated channel was made by [1-30].

The work [1] studies physical processes of free convective current and determines the conditions of cool air filtration in the gap.

The article [8] determines best hydraulic ventilated cavity of a suspended facade. The author of the article [10] estimates the average velocity of free-convective current dependence with different wall temperature.

The author of the work [11] gives the description of air-vent quarter division with different air motion modes. The work [15] determines experimentally and theoretically the average velocity and temperature profiles along the ventilated channel width.

The work [27] provides evaluation methods of thermal insulation with longitudinal air filtration of ventilated facade.

\section{Goal Setting}

- determining of optimal parameters for heat-mass exchange of ventilated air gap of a highrise building

- determining the average velocity and temperature of heat-gravitational flow in air gap with open and sealed grooved lines with constant geometric parameters of the gap

\section{Methods and Results}

Modern high-rise construction impose strict requirements on energy efficiency of the buildings in construction. Consequently, usage of cladding structures with ventilated air cavities in the process of multi-store construction is a common practice.

The main difference between fronts of the building with ventilated air spaces and popular claddings with air cavities is that an air space has metal substructures, a thick heat-insulating layer and a facing layer that defines an architectural look of a building. While the layers with ventilated air cavities are used in low-rise buildings, the fronts with ventilated air spaces are applied in high-rise structures dozens meters high.

Primary advantages of curtain walling with ventilated air cavities are the following:

- Better heat-insulation. Consequently, this technology can help significantly decrease bills on heating system for residents of multi-store houses that have quite a broad front surface.

- Reduction of heat leakage. The system of ventilated curtain walls allows to choose an appropriate type and thickness of the insulation according to climate conditions of the region where the high-rise building is situated.

- Normalization of humidity condition of the cladding structure. This technology protects the insulation from layering and soakage what improves thermal and technical performance of a building. These advantages are provided with air flow in the air cavity. It is performed with wind and gravitational pressure. Non-saturated with moisture vapour air fills the air cavity. Circulating in the air cavity this air absorbs moisture gradually saturating with it. Moisture phase state changes depending on air temperature and cavity surfaces, as well as the mass of the incoming vapor. The increase of the partial vapor pressure changes the degree of air moisture saturation that goes up to the maximum level of saturation. Particular air humidity may cause condensate formation on the cold surface of the air cavity.

Collecting of geometric data for the air cavity such as the width of the air space and availability or absence of grooved lines provides the circulation of air in it what will not cause condensate formation on the cold surface of the air cavity. This process is also directly 
affected by the air velocity in the ventilated air space. The following formula for the average velocity of the thermal and gravitational flow is valid [15]:

$$
v=\varphi \frac{g L}{\sqrt{R T_{c}}} \sqrt{\frac{1}{n}-\frac{1}{k}}
$$

where $\mathrm{R}$ - individual gas constant. For air, approximately, $\mathrm{R}=287 \mathrm{~m}^{2} /\left(\mathrm{c}^{2} \mathrm{~K}\right)$. In connection with simplifications made:

$$
v=\varphi \frac{g L}{\sqrt{R T_{c}}} \sqrt{\frac{k-1}{n k}} \approx \frac{\varphi}{2} \frac{g L}{\sqrt{R T_{C}}}
$$

In nondimensional form the last formula may be written in similarity criteria:

$$
\frac{v}{\sqrt{g L}}=\frac{\varphi}{2} \frac{g L}{\sqrt{R T_{C}}}
$$

Indeed, Froud number for measuring thermal and gravitational flow:

$$
\frac{v}{\sqrt{g L}}=F r
$$

Mach number measuring relation of Langrangian velocity $\sqrt{g L}$ to sound velocity in cold air, $\sqrt{R T_{c}}$

$$
\sqrt{\frac{g L}{R T_{C}}}=B a
$$

As a result:

$$
\begin{aligned}
& \frac{F a}{B a} \varphi \sqrt{\frac{k-1}{k}}=\frac{\varphi}{2} \\
& F r=\varphi \sqrt{2\left(1-\frac{T_{c}}{T_{h}}\right)}
\end{aligned}
$$

Application of similarity variables is useful for modeling of building structures on the laboratory units. We executed several laboratory tests on the stylized scheme of the ventilated air space between hot surface $y=0$ (under the temperature of $\mathrm{Th}=67^{\circ} \mathrm{C}$ ) and cold surface $\mathrm{y}=\mathrm{h}$ (under the temperature of $\mathrm{Tc}=22^{\circ} \mathrm{C}$ ). The pressure at the mark of $\mathrm{z}=0$ is $\mathrm{p}_{0}$, the pressure at the mark of $\mathrm{z}=\mathrm{h}$ is $\mathrm{p}_{1}$, provided that $\mathrm{p}_{0}>\mathrm{p}_{1}$. The average velocity and the temperature in the ventilated air space are required to be assessed.

The necessary control volume covers the air channel and extends from below starting at the zero mark and up to the surface $\mathrm{z}=\mathrm{L}$ that is situated just over the output cutoff of the channel in fixed air. External air must income into the air cavity through lower weep holes. External air goes up along the ventilated air channel and goes out through the upper weep holes. [1] 


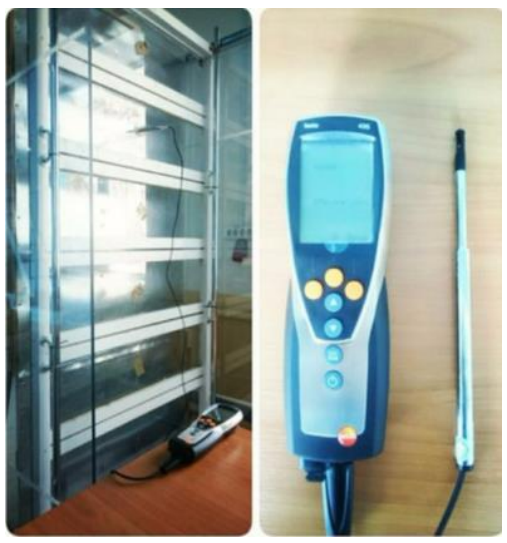

Fig. 1. Installation scheme and measuring instrument

Heating elements fixed along the height of the unit provide the heat rise. In order to distribute the heat equally, these elements are fixed to a tin sheet that has a high thermal conductivity. Consequently, $\mathrm{Th}=$ const. Height of the model is of $\mathrm{L}=204 \mathrm{~cm}$, provided that $\mathrm{L}>>h$.

When modelling a front of the building, we must take into account the temperature difference of internal and external layers explained by functioning of the heating system. Heating of the wall and heat supply from it into the air cavity are taken into account on the model. The velocity depends on the way of air supply into the unit, internal parameters of the cavity and the way of heating the hot surface. The width of the air cavity plays a significant role when building ventilated fronts on real high-rise structures. Usually the air cavity amounts to the width of $60 \mathrm{~mm}$ up to $150 \mathrm{~mm}$. The optimal width of air cavity is defined in connection with:

- type of a facing layer;

- potential wind load;

- structure altitude.

In order to conduct a physical modeling of real multi-store structures, the actual parameters were projected onto a small laboratory model (scaling). The observed models of buildings have the following thickness of ventilated thickness ( $\left.\mathrm{h}_{\text {of the building }}\right)-8 \mathrm{~cm}, 10 \mathrm{~cm}, 12$ $\mathrm{cm}, 15 \mathrm{~cm}, 20 \mathrm{~cm}$, as well as the following altitude ( $\mathrm{L}_{\text {of the building): }}$

- 5 floors $\approx 15 \mathrm{~m}$.

- 9 floors $\approx 30 \mathrm{~m}$.

- 22-25 floors $\approx 80 \mathrm{~m}$.

- Over 30 floors $\approx 100 \mathrm{~m}$.

The altitude of the laboratory unit is $\mathrm{Lm}=2.04$ meters, as a result, the thickness of the ventilated air space is $\left(h_{m}\right)$ is in conversion. Then the value $h_{m}$ is the following Table 1 :

Table 1. The value $h_{m}$.

\begin{tabular}{|c|c|c|c|c|c|}
\hline \multirow{2}{*}{$\begin{array}{c}\text { Building } \\
\text { height, } \mathrm{m}\end{array}$} & \multicolumn{5}{|c|}{ Thickness of the ventilated air space, $\mathrm{m}$} \\
\cline { 2 - 6 } & 0.08 & 0,1 & 0,12 & 0,15 & 0,2 \\
\hline 15 & 0.0112 & 0,014 & 0,0168 & 0,021 & 0,028 \\
\hline 30 & 0.0056 & 0,007 & 0,0084 & 0,0105 & 0,014 \\
\hline 80 & 0.0021 & 0,003 & 0,0032 & 0,0039 & 0,005 \\
\hline 100 & 0.0017 & 0,002 & 0,0025 & 0,0031 & 0,004 \\
\hline
\end{tabular}


Maximum heat-shielding properties of the front design may be achieved with as low as practicable (according to the conditions of the moisture removal or for any other reasons) air space size due to the fact that the thinner the space, the faster it heats up. This is attributed to the height reduction of the temperature in the space and, as a consequence, with the increase of the average air temperature. In the executed tests the width of the space $h$ is set to $h=0,08$ $\mathrm{m}=$ const. Radiant heat exchange occurs between the surfaces of the facing and thermal insulation, with a coefficient of radiant heat exchange depending on the temperature. Convective heat exchange occurs between the air in the space and the elements of the structure, the coefficients of convective heat exchange depend on the velocity of the air flow and air temperature and structural elements.

The velocity and temperature of the air in the space were determined with a uniform heating of the hot surface height along - Fig.2, Fig.3.

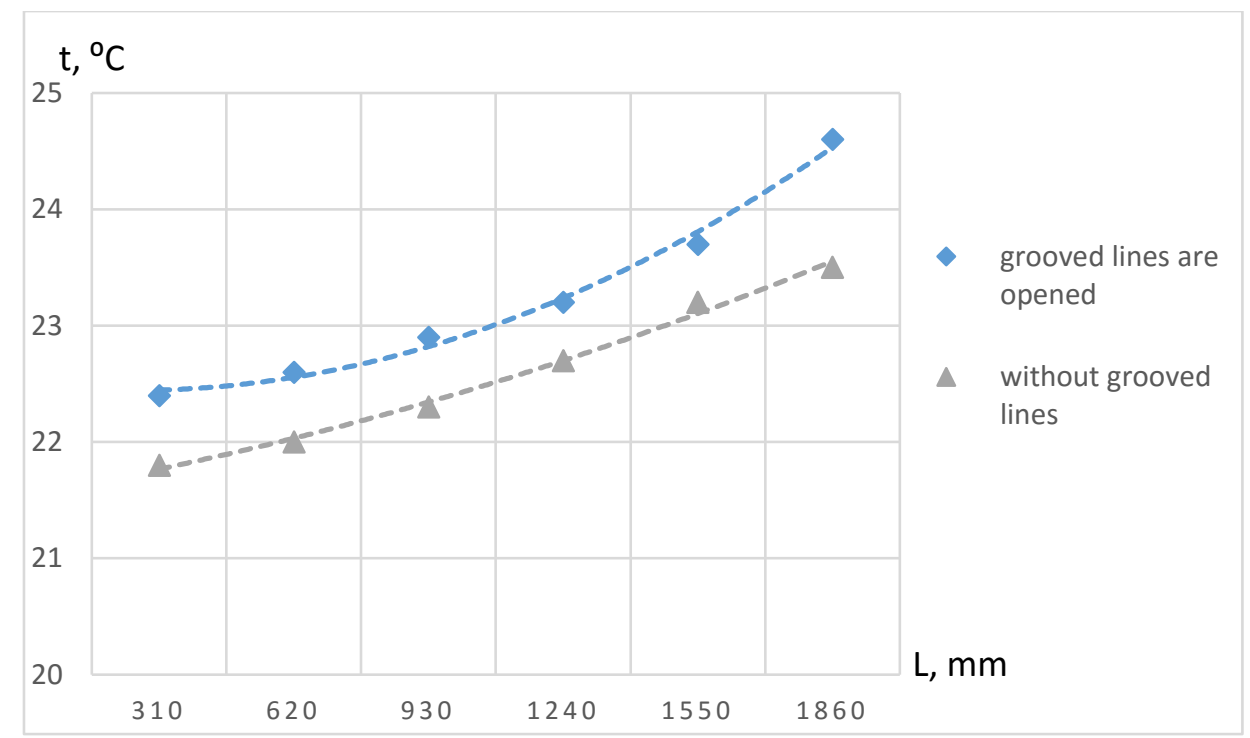

Fig.2. Temperature distribution along the channel

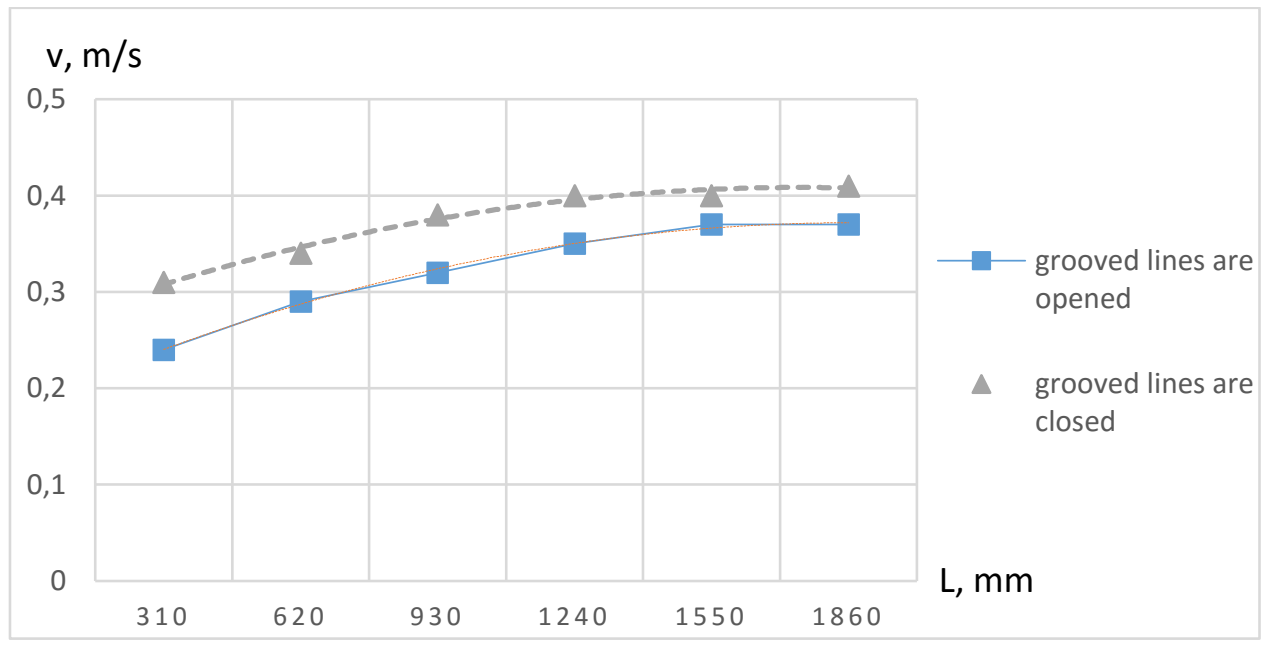

Fig. 3. Velocity distribution along the channel 
The following results show that the air flow velocity in the air space is small and amounts to $1 \mathrm{~m}$ per sec. It depends on its average temperature. In all cases, the velocity of the air flow goes up with the increase of internal air temperature. A double increase in the height of the building front gives a small rise to the air velocity.

Due to ruptures in the facing layer, i.e. grooved lines, the temperature and air flow velocity will "tilt" and deviate from its average value for the height of the ventilated space.

\section{Conclusions}

Ventilated curtain walls are the most spread-out technology in the facade finishing, as well as in the multi-store construction. Advantages of ventilated fronts are obvious compared to the similar technologies.

The front of the building is sensitive to the change in number of grooved lines and the way of heating. The highest velocity is determined with sealed grooved lines (ideal channel), but this system is not yet technically possible today. The best solution is the least number of grooved lines. In this case, moisture does not stay on the external surface of the insulation, but drains through the air space. The correct collecting of geometrical data will help to prevent the condensate formation.

\section{References}

1. D. Nemova, V. Olshevskyi, D. Cejtin. Nauchno-tehnicheskie vedomosti SPBGPU, Jekonomicheskie nauki, 183, 295-301 (2013)

2. A. Ostrovaja, E. Stacenko., V. Olshevskyi., T. Musorina,. MATEC Web of Conferences, 53,1-5 (2016)

3. D. Nemova, V. Emel'janova, D. Miftahova, Magazine of Civil Engineering, 8, 46-53 (2010)

4. V. Emel'janova, D. Nemova, D. Miftahova, Magazine of Civil Engineering, 6, 67-74 (2014)

5. M. Petrichenko, Soviet research, 5 (23), 703-715 (1991)

6. A. Ostrovaja, M. Petrichenko, E. Stacenko, Applied Mechanics and Materials, 725-726 (2015)

7. M. Petrichenko, St. Petersburg State Polytechnical University Journal. Physics and Mathematics, 143-149 (2012)

8. M. Petrichenko, M. Petrochenko, E. Yevtushenko, Magazine of Civil Engineering, 2 (37), 35-40 (2013)

9. N. Vatin, M. Petrichenko, D. Nemova. Applied Mechanics and Materials,633, 10071012 (2014)

10. M. Petrichenko, M. Petrochenko, Magazine of Civil Engineering, 8 (26), 51-56 (2011)

11. A. Girgidov, Hydraulic engineering, 6, (2015)

12. E. Yevtushenko, Construction of Unique Buildings and Structures, 2(7), 55-61 (2013)

13. B. Gebhart, J. Jaluria, R. Mahajan, B. Sammakia, MIR, 5, 678 (1991)

14. V Lapin., S. Lapin, Privolzhsky scientific journal, 2(22), 85-92 (2012)

15. M. Petrochenko, Osnovy gidravlicheskogo rascheta svobodnokonvektivnyh techenij v ograzhdayushchih stroitel'nyh konstrukciyah, (PhD Thesis, St. Petersburg 2012)

16. S. Kornienko, Magazine of Civil Engineering, 2, 18-23, (2012) 
17. M. Petrichenko, M. Petrochenko, Nauchno-tehnicheskie vedomosti SPBGPU, 2, 34-39 (2012)

18. E. Yevtushenko, M. Petrochenko, Magazine of Civil Engineering, 8, 38-45 (2012)

19. D. Nemova., Construction of Unique Buildings and Structures, 84-86 (2012)

20. V. Gagarin., V. Kozlov, Stroitel'naja fizika v XXI veke, 11, 73-80 (2006)

21. V. Bukhartsev, M. Petrichenko, Power Technology and Engineering, 5, 374-377 (2011)

22. J. Li, Y. Chow, Centre for Sustainable Energy Technologies (CSET), 198-203 (2014)

23. J. Hana, L. Penga, Ya. Hongxing, Energy and Buildings, 56, 204-209 (2013)

24. A. Rosca, I. Pop. International Journal of Heat and Mass Transfer, 60, 355-364 (2013)

25. G. Barrios, G. Huelsz, R. Rechtman, J. Rojas, Energy and Buildings, 43, 219-223 (2011)

26. H. Yang Feng, G. Xia, Q. Wan, ISHVAC 2013, 384-396 (2013)

27. L. Gaillard, S. Giroux-Julien, C. Menezo, H. Pabiou,. Chair Habitats and Energy Innovations, 7, 54-67 (2012)

28. D. Zaborova, T. Musorina, M. Petrichenko St. P. State Polytechnical U. Journal, 231,18-26 (2017)

29. M. Petrichenko., N. Vatin, D. Nemova., V. Olshevskiy, Applied Mechanics and Materials.,725, 93-99 (2015)

30. A. Barabash , E. Naumova, O. Zhuvak, D. Nemova, V. Olshevskiy, MATEC Web of Conferences,73, (2016) DOI: 10.1051/matecconf/2016 7302006 